\title{
NN MODELLING OF THE ENERGY CONSUMPTION IN THE WELDING PROCESS
}

\author{
Cezarina AFTENI 1, Gabriel FRUMUSANU 1, Catalina COMSA ${ }^{1}$ \\ 1 "Dunarea de Jos" University of Galati, Manufacturing Engineering Department \\ Email: Cezarina.Afteni@ugal.ro
}

\begin{abstract}
Energy consumption is different for various technological processes used in manufacturing (cutting, plastic deformation, sintering, welding, etc.) and nowadays is becoming a more and more important issue to be considered when planning certain manufacturing processes. Related to this, when releasing a quotation for a given product request coming for the market, it is important to have a tool enabling to evaluate the estimated energy consumption that will be required. This paper proposes a method to predict the consumption of energy in the welding process depending on the same main parameters of the process. The method is based on causal identification and on the NN modelling technique. Method application is sampled in the case of a real database including information concerning pipes welding. The method proves to be fast and delivers results of reasonable precision.
\end{abstract}

KEYWORDS: welding process, energy consumption, NN modelling, causal identification, pipes welding.

\section{INTRODUCTION}

In the $21^{\text {st }}$ century, energy is an inextricable part of life, so its use and availability will become increasingly important with concerns about climate change.

Energy consumption is different for the various technological processes used in manufacturing (cutting, plastic deformation, sintering, welding, etc.).

Welding is the method of non-removable joining of two parts consisting of establishing the chemical bond between the surfaces to be joined, a bond which is made by heating, pressure, or combined with or without external material input.

Welding processes can be classified according to many criteria, the most important being:

- after the state of aggregation of the material during the process in the area of combined;

- according to the temperature at which the joint is made (in close relation with the criterion previous);

- according to the nature of the energy used to make the joint.

Depending on the energy used, there are 3 types of welding:

- electric energy welding (with electric arc, with plasma, with the electron beam by electrical resistance, with the help of high-frequency currents, with photon beam - laser welding),
- chemical energy welding (with flame, aluminiumthermal welding, forging fire welding, by explosion), and

- mechanical energy welding (by friction, by percussion, with ultrasound, by cold pressure).

Until recently, among the selection criteria of the welding process was the need for better weld quality to maximize weld performance in service of higher productivity to reduce the cost and cycle time for welding.

The energy efficiency of the process as one of the criteria for selecting the process is now receiving more attention. Most of these only consider the energy needed to produce the weld. They do not accurately reflect the total energy requirements of a welding process. So, to compare the energy efficiency of each process, it is necessary to consider the total energy consumption.

For the actual system, the process model is the mathematical replica that can replace the actual system for different purposes such as: predictive modelling, optimization, qualitative modelling, classification and control system design.

The process models will continue to play an essential role in hybridizing and developing welding processes and manufacturing in-situ synthesis customized multi-material products, thereby improving the welding processes' efficacy and energy efficiency. 
In paper [1], the authors present the modelling in welding processes by a compilation of techniques for developing welding process models, including statistical, numerical, and soft-computational. The process modelling primary purpose is productivity enhancement through developing a new process or improving upon the existing processes.

A new energy estimation model for remote laser welding was proposed in [2]. This model estimates the total energy, which is consumed by a robot arm, the laser source, and the cooling system. It considers the energy determined by robot operation parameters, arm path, and welding parts instead of the one for the laser melting phenomenon. A mathematical model has been created in paper [3] in order to take a "wholesystem" approach to laser welding electrical demand, accounting for all component subsystems of the laser cell. This model was experimentally tested via the use of an electrical energy monitor to gather energy data for an autogenous welding process at a variety of parameters. To realize high-quality joints, a fundamental coefficient is efficiency as well as the knowledge of the energy flow of the welding processes.

In paper [4], the efficiencies of different groups of welding processes are compared. This paper focuses on the analysis of the energy input into the join measured by different calorimetric systems. In this paper, the authors studied and illustrated the influence of individual welding parameters on the energy balance of the system. Also, the energy balance for a set of different processes and welding parameters (for example, welding current, the distance of the electrode, shielding gas volume, and helium or hydrogen content in the argon shielding gas) was determined. Choi et al. investigate in [5] the energy consumption and resulting weld quality in friction stir butt welds of alumina 6061-T6 plate over a range output power (spindle speed and weld speed). To evaluate energy consumption, both electrical input power (wall plug) and mechanical output power (process) of the friction stir welding machine were monitored. The power is minimized with a combination of the lowest possible spindle speed and weld speed, while the energy consumption is minimized by operating at the highest possible weld speed.

Optimizing the electrical energy consumed is one of the methods in reducing energy consumption in the welding process and supports sustainable manufacturing. In paper [6] the optimized electrical energy consumption in the welding process was determined, based on the optimized welding parameter model. This model produces good quality and energy-efficient welding process.

The reduction of electrical energy consumption benefits the industries in having to reduce the overall cost of the welding process.

The challenge faced in this paper is to develop a tool able to predict the energy consumption in the welding process starting from a few cause-variables characterizing the process, chosen by causal identification. This tool application requires the availability of an instances database and it lays on neural networks technique. The proposed tool may be very important in decision-making when releasing quotations to requests for products coming from the market.

The paper is organized as follows: the next section concerns the analytical modelling of the welding process energetics. The third section deals with NN modelling, with application in welding. The fourth section introduces the suggested method for predicting the consumption of energy in the welding process and samples the method application in welded pipes manufacturing. The last section presents the paper's conclusions.

\section{ANALYTICAL MODELLING}

Analytical modelling consists in determining the calculation relation of the energy consumed depending on the technological parameters of the welding process. These relations/models have different shapes depending on the welding process considered, [7].

Analysis of energy consumption of some welding processes:

- Welded electrode welding and MIG/MAG welding

Electricity consumption depends primarily on the technical characteristics of the source welding and welding parameters used, [7].

The technical norm of time is calculated for a part using the relation:

$$
N_{T}=\frac{T_{p i}}{n}\left(\sum_{j=1}^{k} T_{o p i} l_{j}+t_{a p}\right) K_{d} K_{o} K_{p}[\mathrm{~min} / \mathrm{part}],
$$

where $T_{p i}$ means the preparation and completion time, in $\min /$ lot; $n$ - the number of identical parts being executed; $T_{o p i}$ - the incomplete operating time; $l$ - the length of the weld bead, in $\mathrm{m}$; $t_{a p}$ - the auxiliary time related to the welded part, in $\mathrm{min} /$ part; $K_{d}-$ the coefficient that takes into account the service of the job; $K_{o}-$ the coefficient that takes into account rest time and physiological needs; $K_{p}$ - the coefficient for labour productivity.

The electricity consumption is calculated with the relation:

$$
E=\sum \frac{I_{s j} \cdot U_{a j} \cdot t_{b j} \cdot l_{j}}{\left(6 \cdot 10^{4} \cdot \eta\right)}+\frac{P_{0}\left(N_{T}-\sum t_{b j} l_{j}\right)}{60}[\mathrm{kWh}], \text { (2) }
$$

where $I_{s}$ means the intensity of the welding current, in $\mathrm{A} ; U_{a}$ - the arc voltage, in $\mathrm{V} ; t_{b}$ - the specific base time, relative to the length of the weld bead, in $\mathrm{min} / \mathrm{m} ; \eta$ - the electrical efficiency of the welding source; $\mathrm{P}_{0}-$ the power consumed by the source when idling, in $\mathrm{kW}$. 
- Electrothermal soldering with non-ferrous alloys The electricity consumption is determined with the relation:

$$
E=U_{a \lim } I_{a \lim } \cdot N_{T} /\left(6 \cdot 10^{4}\right)[\mathrm{kWh}],
$$

where $U_{\text {alim }}$ means the supply voltage of the soldering equipment, in V; Ialim - the current of supply of soldering equipment, in $\mathrm{A}$.

- Ultrasonic welding

The time norm is calculated with the relation:

$$
N_{T}=t_{p i}+\left(t_{\text {welding }} t_{\text {auxiliar }}\right) K_{d} K_{o} K_{p}[\mathrm{~min} / \mathrm{part}] \text {, }
$$

where $t_{p i}$ means the preparation time; $t_{\text {welding }}$ - the welding time; $t_{\text {auxiliar }}$ - the time for auxiliary operations.

The electricity consumption is determined with the relation:

$$
E=P_{U S} \cdot t_{U S} /\left(3.6 \cdot 10^{3}\right)[\mathrm{kWh}],
$$

where $P_{U S}$ means the rated power of the ultrasonic equipment, in $\mathrm{W} ; \mathrm{t}_{\mathrm{US}}-$ the execution time of ultrasonic welding itself.

- Friction welding with rotary active element (FSW)

The electricity consumption is determined with the relation:

$$
\begin{aligned}
& E=\left(P_{m_{\text {vert }}} \cdot G_{m_{\text {vert }}} \cdot t_{\text {vert }}+P_{m_{\text {rot }}} \cdot G_{m_{\text {rot }}} \cdot t_{r o t}+\right. \\
& \left.+P_{m_{\text {oriz }}} \cdot G_{m_{\text {oriz }}} \cdot t_{\text {oriz }}\right) \cdot \frac{1}{\left(3.6 \cdot 10^{3}\right)}[\mathrm{kWh}],
\end{aligned}
$$

in which: $\mathrm{P}_{\mathrm{m}_{\text {vert }}}$ means the rated motor power for vertical displacement; $\mathrm{G}_{\mathrm{m}_{\text {vert }}}-$ its degree of load; $\mathrm{t}_{\text {vert }}$ - the actuation time of his; $\mathrm{P}_{\mathrm{m}_{\text {rot }}}$ - the rated motor power for rotational motion; $\mathrm{G}_{\mathrm{m}_{\text {rot }}}$-its degree of load; $t_{\text {rot }}$ - its running time; $\mathrm{P}_{\mathrm{m}_{\text {oriz }}}-$ the rated motor power for horizontal displacement; - its degree of load; $t_{\text {oriz }}$ - the actuation time.

- Welding of polyethylene pipes

The time norm is calculated with the relation:

$$
\begin{aligned}
& N_{T}=t_{p}+\left(t_{\text {milling }}+t_{\text {heating }}+t_{\text {discharg }}\right) \\
& \cdot K_{d} \cdot K_{o} \cdot K_{p}[\mathrm{~min} / \mathrm{part}],
\end{aligned}
$$

where: $t_{p}$ means the preparation time; $t_{\text {milling }}$ - the milling time; $t_{\text {heating }}$ - the heating time; $t_{\text {discharge }}$ - the discharge time.

The electricity consumption is determined with the relation:

$$
\begin{aligned}
& E=\left[P_{\text {milling }} \cdot t_{\text {milling }}+P_{\text {hob }} \cdot t_{\text {heating }}+P_{\text {pump }} \cdot t_{\text {pump }} \mid\right. \\
& /\left(3.6 \cdot 10^{3}\right)[\mathrm{kWh}],
\end{aligned}
$$

in which: $P_{\text {milling }}$ means the rated power of the milling cutter motor; $P_{h o b}-$ the rated power of the electric heating hob a pipe ends; $P_{\text {pump }}$ - the power nominal hydraulic pump motor for discharge; $t_{\text {pump }}-$ the operating time of pump motor.

\section{NEURAL NETWORK APPLIED IN WELDING PROCESSES MODELING}

This section presents some of the existing researches on the application of neural networks in welding process modelling.

In recent years, special attention is paid to modelling and simulation with neural networks for applications in the welding process.

Neural modelling is a concept widely used in theoretical research but is at the beginning of the road in practical areas.

Artificial neural networks represent artificial intelligence systems created with an aim to imitate functions of the human brain and biological neurons and to be applied in solving different problems which require performing complex operations, [8].

Artificial neural networks have proved useful in a variety of real-world applications that deal with complex and highly interactive processes, like pattern recognition, speech recognition, finance, medicine, sales predicting, weather forecasting, and monitoring and control of manufacturing processes. The advantage of this approach is that modelling can be done using experimental data without having to make any simplifying assumptions.

Artificial neural network (ANN) is effectively used for modelling manufacturing processes such as metal cutting, forming, etc.

Artificial neural networks represent artificial intelligence systems created with an aim to imitate functions of the human brain and biological neurons and to be applied in solving different problems which require performing complex operations.

Figure 1 shows the general structure of an artificial neural network. The artificial neuron is modelling the behaviour of a real neuron. The connections between neurons, called synaptic weights, are used in information storage.

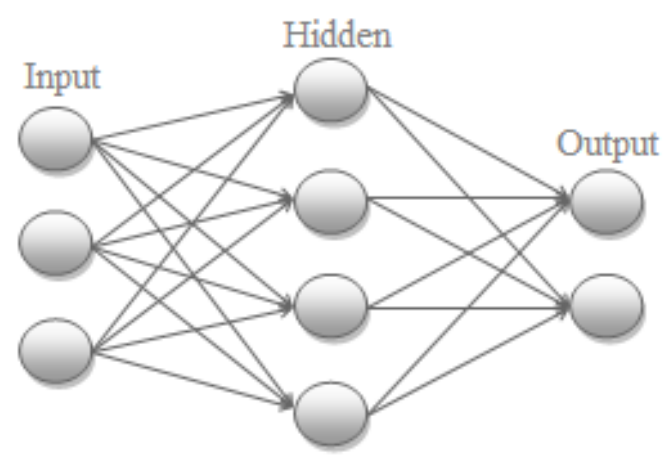

Fig. 1. Artificial neural network, [8] 
The proposed architecture of neural network (NN) consists of three layers:

- input layer,

- hidden layer, and

- output layer.

The input layer consists of all the input factors. Information from the input layer is then processed in the hidden layer. Outputs of the hidden layer(s) are also computed in the output layer and the results are obtained in the output vector.

There are many types of research in which neural networks were used to model the unknown relations between different parameters of the welding process, such as: the welding speed, the welding current intensity, the tool rotational speed.

Paper [9] proposed an alternative method to predict FSW parameters and make a decision using a modified version of the adaptive neuro-fuzzy inference system (ANFIS) integrated with harris hawks optimizer (HHO). HHO was used to search for optimal values of ANFIS parameters and to determine the optimal operating conditions of the FSW process. The shared effect of welding speed, tool rotational speed, and plunge force on the mechanical properties of welded aluminium plates was simulated.

Paper [10] addresses the weld joint strength monitoring in the pulsed metal inert gas welding (PMIGW) process. A multilayer neural network model has been developed to predict the ultimate tensile stress (UTS) of welded plates. The training and testing of the ANN model have been done using 53 experimental datasets, which were obtained from response surface analysis. The performance of the neural network is compared with the regression model, which has been developed from the same experimental datasets used for the neural network.

In paper [11], a tungsten inert gas (TIG) welding process has been modelled by using a conventional linear regression technique, a back-propagation neural network (BPNN), and a genetic-neural system (GA-NN).

This paper [12] focuses on the microstructural and mechanical properties of the Friction Stir Welding (FSW) of aluminium alloys. An Artificial Neural Network (ANN) model was developed to simulate the correlation between the FSW parameters and mechanical properties. In order to train the ANN model, 16 patterns of the experimental results were employed. The testing of the ANN model was carried out using four patterns.

The present study [13] focuses on friction welding process parameter optimization using a hybrid technique of ANN and different optimization algorithms. ANN based approaches could model this welding process in both forward and reverse directions efficiently, which are required for the automation of the same. Five different training algorithms were used to train ANN for both forward and reverse mapping. ANN tuned force approach was used for optimization.

Ates presents in [14] a novel technique based on artificial neural networks (ANNs) for the prediction of gas metal arc welding parameters. The aim of this study was to show the possibility of the use of neural networks for the calculation of the mechanical properties of welded low alloy steel using the GMA method. The proposed novel technique developed in this work shows that good performance of the ANN model was achieved.

In work [15], an artificial neural network (ANN) was implemented to investigate the main effects of process parameters on the laser welding process quality. Process parameters were optimized according to both experimental trials and computational data. The target of the proposed ANN architecture allowed predicting, integrating and controlling the laser welding process.

As it can be noticed, the NN modelling has been widely applied in welding processes modelling, with diverse proposes. The obtained results are encouraging and sustain the idea of extending $\mathrm{NN}$ modelling application for predicting the energy consumption in welding processes.

\section{ENERGY MODELING OF THE WELDING PROCESS USING NEURAL NETWORKS}

The need for evaluation appears whenever:

i) an analysis 'what if' is performed to adopt an alternative to proceed in manufacturing process case, and

ii) the characteristics of the task that have the greatest impact on the effect (objective) must be determined in order to effectively control the manufacturing process, [16].

This evaluation requires the existence of a model, therefore, finding the model of the considered process is a matter of general interest. However, such a model can be complicated, involving many variables, so finding it is difficult. In addition, the applicability of the model is limited - if the premises on which the model was determined are modified, it may become useless or, in the best case - inaccurate.

Model construction involves two stages:

1. Model structure establishment, which means, first of all, the selection of the cause-variables by which the effect-variable can be evaluated and based on which the future model will be built (which supposes, at first, the selection of model variables).

2. Model formalization (through the concrete relation linking the effect-variable to the cause-variables) for example, starting from a parametric model, the parametric values are adjusted until the model properly expresses, in a quantitative way, the causal link. 
The core idea in finding causal models is to look for relations between the variations of cause-variables and effect-variables instead of viewing each instance as an event that illustrates the causal relation between these variables, [17].

In this section, an application that enables a manager to a make quick decision, effectively evaluates a feature of the manufacturing process and establishes the optimal option for making some products through neural networks, was developed. Both stages of model construction are addressed.

A database with real data extracted from the industrial environment, in the welding process of pipelines case was used for the mentioned purpose. The considered objective function was the linear energy consumption.

The following set of six cause-variable was considered as having potential in linear energy consumption modelling in pipelines welding process: the pipe diameter $D$, the sheet thickness $g$, the flow limit $R$ (this being used to identify the material used), the welding current intensity $I$, the welding current voltage $U$ and the welding speed $v_{s}$.

The linear energy consumed $E_{l}$ was chosen as the effect-variable.

The database is composed of seven columns:

- First six, for cause-variables, and

- The last, for result-variable.

The values of the result-variable were calculated with relation:

$$
E_{l}=\frac{60 \cdot \eta \cdot U_{a} \cdot I_{s}}{v_{s}}[\mathrm{~J} / \mathrm{cm}],
$$

A number $n$ of 264 instances was considered. Some of them are sampled in Table 1.
The calculated values of the result-variable will not be transmitted to the NN, these following are to be used only for comparison with the ones that will result from modelling.

The NN modelling has been performed in MatLab.

The simulation of method application was performed in two cases:

- By considering the entire database, all six causevariables and all 254 instances being used, and

- By considering a smaller database, obtained from the initial one by keeping a smaller number of both cause-variables and instances were used (i.e. three cause-variables and 14 instances).

The following application was developed and used in order to perform the mentioned simulation, in the first case from above:

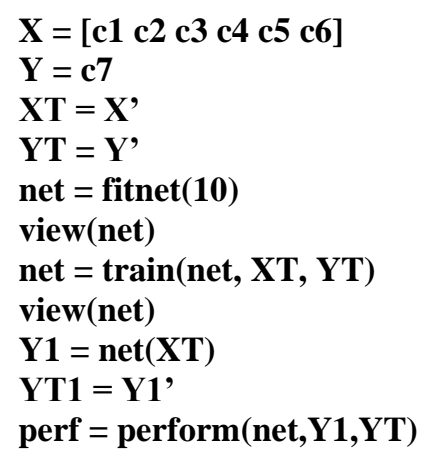

The following notations were introduced: cl means the pipe diameter; $c 2$ - the sheet thickness; $c 3$ - the flow limit; $c 4$ - the welding current intensity; $c 5$ - the welding current voltage; $c 6$ - the welding speed, and $c 7-$ the linear energy.

Table 1. Real instances database

\begin{tabular}{|c|c|c|c|c|c|c|c|}
\hline $\begin{array}{c}\text { Instance } \\
\text { crt. no. }\end{array}$ & $\begin{array}{c}\mathrm{D} \\
{[\mathrm{mm}]}\end{array}$ & $\begin{array}{c}\mathrm{g} \\
{[\mathrm{mm}]}\end{array}$ & $\begin{array}{c}\mathrm{R} \\
{[\mathrm{MPa}]}\end{array}$ & $\begin{array}{c}\mathrm{I} \\
{[\mathrm{A}]}\end{array}$ & $\begin{array}{c}\mathrm{U} \\
{[\mathrm{V}]}\end{array}$ & $\begin{array}{c}\mathrm{v}_{\mathrm{s}} \\
{[\mathrm{m} / \mathrm{min}]}\end{array}$ & $\begin{array}{c}\mathrm{E}_{\mathrm{l}} \\
{[\mathrm{J} / \mathrm{cm}]}\end{array}$ \\
\hline 1 & 508 & 6.4 & 360 & 600 & 33 & 0.6 & 1782.0126 \\
\hline 2 & 508 & 6.4 & 360 & 625 & 33.5 & 0.6 & 1884.3969 \\
\hline 3 & 508 & 6.4 & 360 & 650 & 34 & 0.6 & 1989.0487 \\
\hline 4 & 508 & 7.1 & 360 & 605 & 33.1 & 0.6 & 1802.3053 \\
\hline 5 & 508 & 7.1 & 360 & 640 & 33.5 & 0.6 & 1929.6097 \\
\hline 6 & 508 & 7.1 & 360 & 648 & 33.8 & 0.6 & 1971.2390 \\
\hline$\ldots$ & \multicolumn{7}{|c|}{................ } \\
\hline 138 & 762 & 7.9 & 360 & 649 & 34 & 0.6 & 1986.0347 \\
\hline 139 & 762 & 8.7 & 360 & 628 & 33.6 & 0.6 & 1899.1067 \\
\hline 140 & 762 & 8.7 & 360 & 627 & 33.3 & 0.6 & 1879.1108 \\
\hline 141 & 762 & 8.7 & 360 & 641 & 33 & 0.6 & 1903.7861 \\
\hline 142 & 762 & 9.5 & 360 & 750 & 34 & 0.6 & 2294.9641 \\
\hline$\ldots$ & \multicolumn{7}{|c|}{$\ldots \ldots \ldots \ldots \ldots \ldots$} \\
\hline 261 & 1067 & 19.1 & 360 & 935 & 37 & 0.4 & 4673.308033 \\
\hline 262 & 1420 & 9.5 & 360 & 750 & 34.8 & 0.6 & 2349.008698 \\
\hline 263 & 1420 & 9.5 & 360 & 800 & 34.3 & 0.6 & 2469.583867 \\
\hline 264 & 1420 & 9.5 & 360 & 755 & 35 & 0.6 & 2378.263899 \\
\hline
\end{tabular}


Regarding the simulation of method application (entire database case), the following steps were completed:

P1. Importing data into the workspace: $\mathrm{c} 1, \mathrm{c} 2, \mathrm{c} 3, \mathrm{c} 4$, c5, c6, c7.

$\mathrm{P} 2$. Creating the $\mathrm{X}$ matrix: $\mathrm{X}=[\mathrm{c} 1 \mathrm{c} 2 \mathrm{c} 3 \mathrm{c} 4 \mathrm{c} 5 \mathrm{c} 6]$.

$\mathrm{P} 3$. Create the $\mathrm{Y}$ matrix: $\mathrm{Y}=\mathrm{c} 7$.

$\mathrm{P} 4$. Transposed to the matrix $\mathrm{X}: \mathrm{XT}=\mathrm{X}$ '.

$\mathrm{P} 5$. Transposed to the matrix $\mathrm{Y}: \mathrm{YT}=\mathrm{Y}$ '.

P6. The neural network construction with a hidden layer of size 10: net $=$ fitnet(10).

P7. The network visualization: view(net).

P8. Network training using the entire database: net $=\operatorname{train}($ net, $X \mathrm{~T}, \mathrm{YT})$.

P9. The network visualization: view(net).

P10. Estimation using the trained network: $\mathrm{Y} 1=\operatorname{net}(\mathrm{XT})$.

$\mathrm{P} 11$. Transposed to the matrix Y1: YT1 = Y1'.

P12. Trained network performance evaluation: perf $=\operatorname{perform}($ net, $Y 1, Y T)$.

The resulted values for the effect-variable after the simulation on the entire database, as well as the comparison with the results calculated using the relation (9), are presented in Table 2.

Table 2. The effect-variable values

\begin{tabular}{|c|c|c|}
\hline $\begin{array}{l}\text { Instance } \\
\text { crt. no. }\end{array}$ & $\begin{array}{c}E_{l}[\mathrm{~J} / \mathrm{cm}] \\
\text { (calculated results) }\end{array}$ & $\begin{array}{c}E_{l}[\mathrm{~J} / \mathrm{cm}] \\
\text { (simulation results) }\end{array}$ \\
\hline 1 & 1782.0126 & 1781.3378 \\
\hline 2 & 1884.3969 & 1885.84 \\
\hline 3 & 1989.0487 & 1993.8318 \\
\hline 4 & 1802.3053 & 1800.4958 \\
\hline 5 & 1929.6097 & 1929.5883 \\
\hline 6 & 1971.2390 & 1973.0930 \\
\hline 7 & 1843.1616 & 1841.2295 \\
\hline$\ldots$ & \multicolumn{2}{|l|}{ 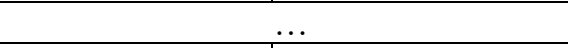 } \\
\hline 137 & 1870.9104 & 1872.6887 \\
\hline 138 & 1986.0347 & 1985.9925 \\
\hline 139 & 1899.1067 & 1897.7937 \\
\hline 140 & 1879.1108 & 1876.4286 \\
\hline 141 & 1903.7861 & 1899.3506 \\
\hline 142 & 2294.9641 & 2294.2144 \\
\hline \multicolumn{3}{|l|}{$\ldots$} \\
\hline 225 & 3898.7895 & 3899.9209 \\
\hline 226 & 3796.2226 & 3792.8749 \\
\hline 227 & 3752.3547 & 3749.5839 \\
\hline 228 & 3665.2028 & 3661.2411 \\
\hline 229 & 4236.3839 & 4239.0351 \\
\hline$\ldots$ & \multicolumn{2}{|c|}{$\ldots$} \\
\hline 260 & 4714.4716 & 4719.2002 \\
\hline 261 & 4673.3080 & 4666.7212 \\
\hline 262 & 2349.0086 & 2348.2391 \\
\hline 263 & 2469.5838 & 2468.1307 \\
\hline 264 & 2378.2638 & 2377.8503 \\
\hline
\end{tabular}

Figure 2 shows the performance of the developed network, assessed on the basis of correlation coefficient ( $\mathrm{R}$ value) between the output values and the target values for the test data.
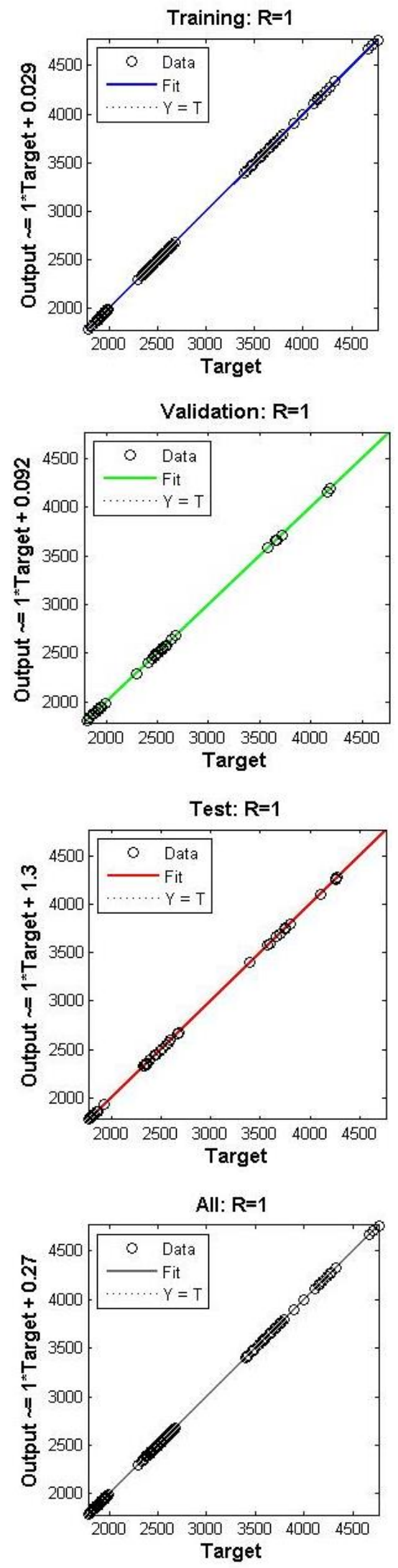

Fig. 2. The value of $R$ coefficient - $c 1, c 2, c 3, c 4, c 5$, c6 cause-variables used for modelling 
Figure 3 presents the error histogram when $\mathrm{c} 1, \mathrm{c} 2$, c3, c4, c5, c6 cause-variables were used for modelling.

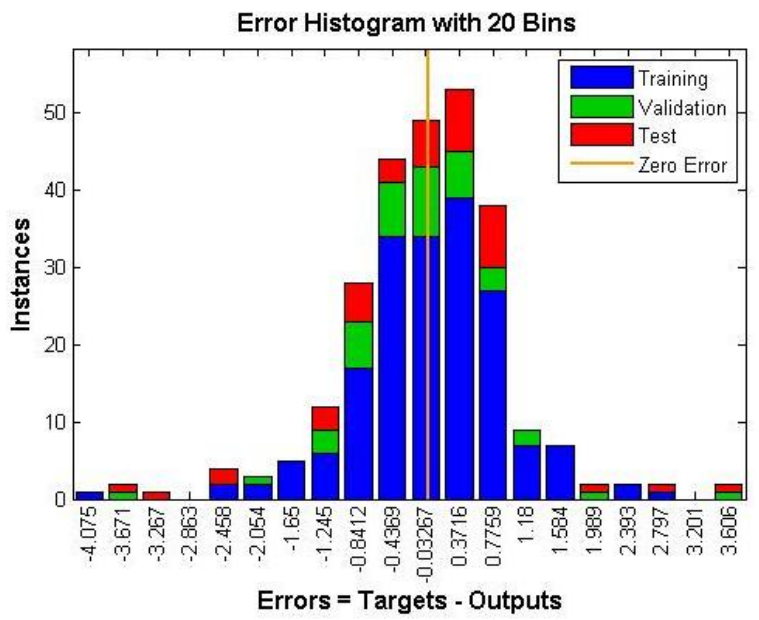

Fig. 3. Example of error histograms - c1, c2, c3, c4, c5, c6 cause-variables used for modelling

Regarding the simulation of method application using a smaller database, obtained from the initial one by keeping a smaller number of cause-variables (namely three cause-variables), and 14 instances.

The same steps presented for the entire database case were also adopted for simulation when using three cause-variables, namely c1, c2, and c4.

Table 3 presents the results values for the effectvariable after the simulation using a smaller database, as well as the comparison with the results calculated using the relation (9).

Table 3. The effect-variable values (reduced instances database)

\begin{tabular}{|c|c|c|}
\hline $\begin{array}{c}\text { Instance } \\
\text { crt. no. }\end{array}$ & $\begin{array}{c}E_{l}[\mathrm{~J} / \mathrm{cm}] \\
\text { (calculated results) }\end{array}$ & $\begin{array}{c}E_{l}[\mathrm{~J} / \mathrm{cm}] \\
\text { (simulation results) }\end{array}$ \\
\hline 1 & 2346.1342 & 2346.0723 \\
\hline 2 & 2428.8979 & 2591.8595 \\
\hline 3 & 1950.4642 & 1950.3932 \\
\hline 4 & 1853.2945 & 1855.0879 \\
\hline 5 & 1952.6707 & 1952.5913 \\
\hline 6 & 1856.2480 & 1856.2578 \\
\hline 7 & 1986.0347 & 1985.9301 \\
\hline 8 & 1899.1067 & 1882.8201 \\
\hline 9 & 1959.7556 & 1959.6416 \\
\hline 10 & 1861.0940 & 1861.0439 \\
\hline 11 & 3898.7895 & 3898.7984 \\
\hline 12 & 3796.2226 & 3796.1881 \\
\hline 13 & 2555.0851 & 3271.8839 \\
\hline 14 & 3644.9755 & 3644.9893 \\
\hline
\end{tabular}

Figure 4 shows the NN-model performance when using a smaller database.

Figure 5 presents the error histogram when c1, c2, c4 cause-variables were used for modelling.
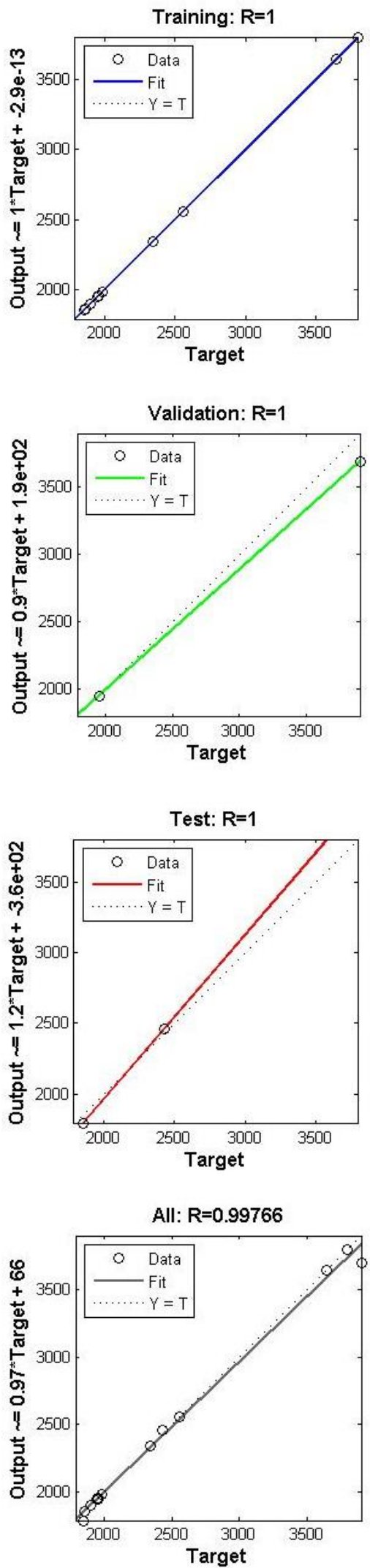

Fig. 4. The value of $R$ coefficient - c1, c2, c4 causevariables used for modelling 


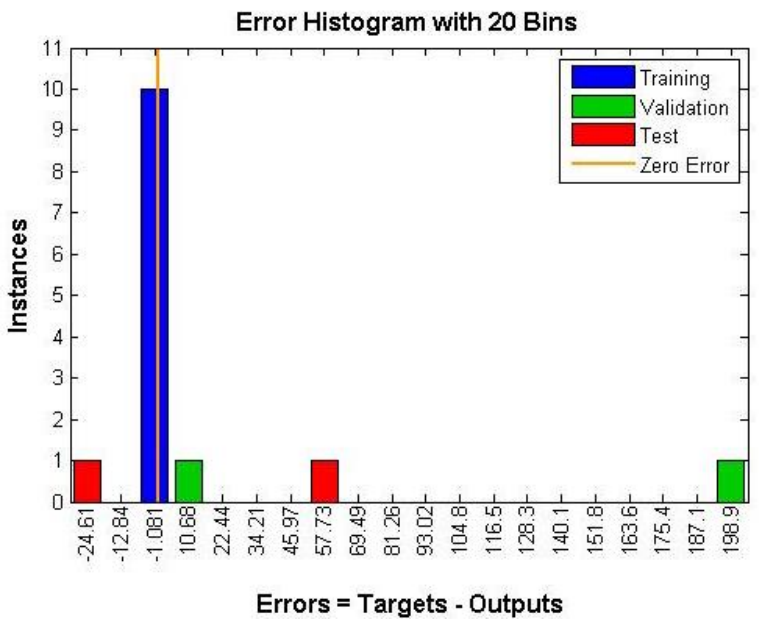

Fig. 5. Example of error histograms - c1, c2, c4 cause-variables used for modelling

For assessing the quality of the results obtained by NN simulation, they were compared to the ones that resulted from analytical modelling. The comparison was performed by calculating the correlation coefficient $r$ between the two series of values.

- The correlation coefficient is $r=0.999985$, if $\mathrm{c} 1$, c2, c3, c4, c5, c6 cause-variables were used for modelling, and

- The correlation coefficient is $r=0.970475$, if $\mathrm{c} 1$, c2, c4 cause-variables were used for modelling.

It can be noticed that the correlation coefficient value, in both simulated cases, is near one, so there is a very good correlation between them.

The case in which all the 6 cause-variables were considered as input data, a much more precise modelling of the energy value was obtained, a fact also proved by the correlation coefficient value: $r=0.999985$.

\section{CONCLUSIONS}

This paper presents a method to predict the consumption of energy in the welding process, depending on some of the process main parameters.

The method is based on causal identification and on the NN modelling technique.

The NN-model performance was evaluated through the values of the correlation coefficient between output and target values and through the histogram of the errors.

The quality of the results obtained by NN simulation was assessed by comparison to the results obtained in the same cases by analytical modelling.

The simulation results of method application are true and when using a small number of cause-variables.

It can be stated, on the basis of the obtained results, that the NN-model generated by using more information has better performance (as it would be expected). At the same time, the values of the energy consumption delivered by NN modelling show a better correlation with the calculated ones when the entire instances' database was used.
The final conclusion is that the here proposed method proves to work fast and the delivered results have good precision, so the method may be successfully implemented in practice.

\section{REFERENCES}

[1] Sharma, A., Process modelling in welding, ElsevierWoodhead, 2021.

[2] Um, J., Stroud, I., Total energy estimation model for remote laser welding process, Procedia CIRP, vol. 7, pp. 658663, 2013.

[3] Goffin, N., Jones, L., Tyrer, J., Ouyang, J., Mativenga, P., Woolley, E., Mathematical modelling for energy efficiency improvement in laser welding, Journal of Cleaner Production, vol. 322, 2021.

[4] Haelsig, A., Mayr, P., Kusch, M., Determination of energy flows for welding processes, Cross Mark, vol. 60, no. 2, pp. 259-266, 2016.

[5] Choi, W. J., Morrow, J., Pfefferkorn, F., Zinn, M., Welding parameter maps to help select power and energy consumption of friction stir welding, Journal of Manufacturing Processes, vol. 33, pp. 35-42, 2018.

[6] Rajemi, M. F., Abu Seman, M. T., Sustainable Energy Efficiency for MIG Welding Process, International Journal of Innovative Technology and Exploring Engineering, vol. 8, no. 5s, pp. 287-291, 2019.

[7] Verbitchi, V., Promovarea unor procese de îmbinare ecologice și cu consum energetic redus (Eng. Promoting joint processes environmentally friendly and energy efficient), project no. PN 09-160107, coordinator: ISIM Timişoara.

[8] Afteni, C., Frumusanu, G., Comparative assessment by neural networks modeling, The Annals of "Dunarea Jos" Univity of Galati, Fascicle V, Technologies Machine Building, pp. 35-40, 2018.

[9] Shehabeldeen, T. A., Elaziz, M. A., Elsheikh, A. H., Zhou, J., Modeling of friction stir welding process using adaptive neuro-fuzzy inference system integrated with harris hawks optimizer, Journal of Materials Research and Technology, vol. 8, no. 6 , pp. 5882-5892, 2019.

[10] Pal, S., Pal, S. K., Samantaray, A. K., Artificial neural network modeling of weld joint strength prediction of a pulsed metal inert gas welding process using arc signals, Journal of Materials Processing Technology, vol. 202, no. 1-3, pp. 464474, 2008.

[11] Dutta, P., Pratihar, D. K., Modeling of TIG welding process using conventional regression analysis and neural network-based approaches, Journal of Materials Processing Technology, vol. 184, no. 1-3, pp. 56-68, 2007.

[12] Shojaeefard, M. H., Behnagh, R. A., Akbari, M., Givi, M. K. B., Farhani, F., Modelling and Pareto optimization of mechanical properties of friction stir welded AA7075/AA5083 butt joints using neural network and particle swarm algorithm, Materials \& Design, vol. 44, pp. 190-198, 2013.

[13] Anand, K., Barik, B. K., Tamilmannan, K., Sathiya, P., Artificial neural network modeling studies to predict the friction welding process parameters of Incoloy $800 \mathrm{H}$ joints, Engineering Science and Technology, an International Journal, vol. 18, no. 3, pp. 394-407, 2015.

[14] Ates, H., Prediction of gas metal arc welding parameters based on artificial neural networks, Materials and Design, vol. 28, no. 7, pp. 2015-2023, 2007.

[15] Casalino, G., Facchini, F., Mortello, M., Mummolo, G., ANN modelling to optimize manufacturing processes: the case of laser welding, IFAC-PapersOnLine, vol. 49, no. 12, pp. 378-383, 2016

[16] Afteni, C., Optimizarea holistică a procesului de fabricație (Holistic optimization of manufacturing process), Doctoral Thesis, „Dunarea de Jos” University of Galati, 2020.

[17] Frumusanu, G. R., Afteni, C., Epureanu, A., Datadriven causal modelling of the manufacturing system, Transactions of Famena, vol. 45, no. 1, pp. 43-62, 2021. 